Short Communication

\title{
Preparation of Iron Tetradecanoate Coating on the Surface of Mg-Li Alloy and Its Corrosion Resistance
}

\author{
Xiaoyuan Zheng ${ }^{2}$, Huan Sheng Lai ${ }^{1, *}$, Zilong Zhao ${ }^{3, *}$ \\ ${ }^{1}$ Sino-French Institute of Nuclear Engineering and Technology, Sun Yat-sen University, Zhuhai \\ 519082, China \\ ${ }^{2}$ School of Mechanical Engineering and Automation, Fuzhou University, Fuzhou 350116, China \\ ${ }^{3}$ School of Chemical Engineering and Technology, Sun Yat-sen University, Zhuhai 519082, China \\ *E-mail: sheng158@,hotmail.com, zhaozlong@mail.sysu.edu.cn
}

doi: $10.20964 / 2021.01 .28$

Received: 5 September 2020 / Accepted: 28 October 2020 / Published: 30 November 2020

\begin{abstract}
Magnesium alloys were commonly used in the industry, but their lower corrosion resistance limited to their application. In this work, an iron tetradecanoate $\left(\mathrm{Fe}\left(\mathrm{CH}_{3}\left(\mathrm{CH}_{2}\right)_{12} \mathrm{COO}\right)_{3}\right)$ coating was on the surface of Mg-7Li-3Al-1Si alloy prepared using an environment friendly method by one-step in order to improve the corrosion resistance of $\mathrm{Mg}$ alloy. Results showed that the prepared coating has an ideal corrosion resistance and a good protection performance.
\end{abstract}

Keywords: Mg-Li-Al-Si alloy, One-step method, coating, Microstructure, corrosion protection

\section{FULL TEXT}

(C) 2021 The Authors. Published by ESG (www.electrochemsci.org). This article is an open access article distributed under the terms and conditions of the Creative Commons Attribution license (http://creativecommons.org/licenses/by/4.0/). 